\title{
Ética na pesquisa agropecuária: percepção dos pesquisadores da Embrapa
}

Regina Lucia Ramos Lourenço e Marcel Bursðtyn

\section{Introdução}

No mundo moderno, avança a percepção de que os cientistas são responsáveis pelos conhecimentos que produzem, como assinala Hans Jonas (1991, p.133), ao evocar o Princípio da Responsabilidade, "O homem é o único ser conhecido que pode ter responsabilidade. Na medida em que ele a pode ter, ele a tem. A capacidade de responsabilidade significa já a colocação sob seu imperativo: o próprio poder leva consigo o dever".

Têm surgido questionamentos sobre a ciência e sua atuação: são necessárias as discussões sobre ética na ciência? A ciência pode estar dissociada de seus resultados? Os cientistas devem considerar os impactos político e social de suas pesquisas? Os cientistas estão isentos da responsabilidade sobre o uso dos conhecimentos que ajudaram a produzir? Esses questionamentos surgem no momento em que se expressa na sociedade, por um lado, o distanciamento do homem em relação aos princípios éticos elementares e, por outro, a exigência, a 
expectativa e a busca determinada por esses princípios fundamentais para a manutenção da vida e a melhoria da qualidade de vida das pessoas.

A necessidade de estar e se mostrar em conformidade com princípios éticos se torna cada vez mais evidente para as organizações, pois a sociedade exige cada vez mais segurança no desenvolvimento e na aplicação da ciência. Com a aceleração do ritmo de avanço da ciência e das suas aplicações a processos diversos, aumentam as dúvidas quanto a seus efeitos diretos e indiretos. Problemas associados ao meio ambiente, à saúde e ao comportamento humano, à geopolítica, ao direito e à justiça social, entre outros campos, são evocados como alerta para o imperativo de se dispor de mecanismos de regulação da ciência. Atualmente há forte tendência a se estabelecer, nas instituições de pesquisa, práticas que permitem assegurar o cumprimento de códigos de conduta (deontologias) e a observância de princípios éticos consagrados.

Em uma sociedade democrática e consciente, os indivíduos, que são ao mesmo tempo financiadores e usuários do avanço em ciência e tecnologia (C\&T), passam a se interessar e exigir transparência e ética nos processos de geração e uso de conhecimentos. Isso significa amplo espectro de iniciativas, que vão dar garantias de qualidade aos produtos, passando pelas implicações de seu uso, até mesmo aos procedimentos (técnicos, sociais, legais) empregados na sua produção.

Além de exigências pela sociedade, que tende a constituir base legal, a conduta ética é um diferencial importante, na medida em que a sociedade começa a cobrar ações em sintonia com o paradigma de um desenvolvimento que obedeça a critérios de sustentabilidade. Dessa forma, a sociedade tem valorizado empresas e organismos que, além de cumprirem com competência sua missão, têm também realizado isso de forma ética, preservando o meio ambiente e a vida, e contribuindo de alguma forma para a justiça social.

Uma evidência dessa tendência é o papel de destaque que o tema "ética na pesquisa" vem ocupando no Brasil e no exterior, se materializando em exigências da inserção de tais aspectos nos projetos de pesquisa. No Brasil já é fato a exigência de avaliação ética em diversos segmentos de pesquisa - seres humanos, bioética, experimentação animal. $\mathrm{Na}$ Europa, essa dimensão ética começa a ser uma exigência das agências de financiamento e instituições de pesquisa para aprovação de projetos. Como exemplo dessa tendência internacional, cita-se um manual publicado em 2007, contendo instruções para pesquisadores (PAuWEls, 2007). O documento serve de referência à elaboração e implementação de projetos de pesquisa financiados pela União Europeia, que passaram a exigir a consideração dos aspectos éticos na condução dos trabalhos de pesquisa por consultores independentes, visando garantir que as pesquisas e atividades sejam realizadas conforme princípios éticos fundamentais.

A Embrapa, empresa pública, ligada ao segmento agropecuário brasileiro, organização na qual foi realizado este estudo, tem a missão de "viabilizar soluções de pesquisa, desenvolvimento e inovação para a sustentabilidade da agricultura, em benefício da sociedade brasileira" (BRASIL, 2008, p.18). Procedimentos associados à ética na pesquisa podem ser observados já na definição da missão da Empresa, mas se entende que esses devem ser acompanhados de práticas de gestão que favoreçam a sua implementação por parte de 
todos os atores, -os quais devem estar envolvidos e comprometidos com tais questões. Entretanto, dois elementos são essenciais: consciência e regulações. $\mathrm{Ou}$, em uma palavra, responsabilidade (institucional e individual). Isso exige mudanças de comportamento e de práticas, indo além da mera adoção de códigos de conduta.

Essa pesquisa visa responder às seguintes questões: em que princípios os cientistas da Embrapa se pautam para realizar a pesquisa agropecuária? Quais os princípios éticos que a Empresa persegue na execução da sua missão de pesquisa? $\mathrm{O}$ que os pesquisadores pensam sobre ética na pesquisa agropecuária? Buscou-se, ainda, entender e analisar como os pesquisadores percebem a questão da ética na pesquisa em geral, e verificar se os princípios éticos estão de fato contidos nas normas e demais documentos da Empresa.

\section{C\&T e ética}

Ciência, tecnologia e inovação (CT\&I) "são elementos essenciais ao crescimento, à competitividade e ao desenvolvimento de empresas, regiões e países... Também têm importância fundamental na determinação do estilo de desenvolvimento de regiões ou nações e na forma como esse afeta no presente e afetará no futuro a qualidade de vida da população em geral e de seus diversos segmentos" (VIOTTI e Macedo, 2003, p.21).

Entretanto, conforme assinalam vários autores, tem havido mudança na interação entre a ciência e a sociedade, que questiona a ciência como atividade própria e restrita aos cientistas, para que se torne um campo também de interesse do público leigo. Nesse processo haveria certa perda do status da ciência como "torre de marfim" ou, pelo menos, o seu deslocamento em alguma medida na escala de prestígio social (MERTON, 1970; RAVETZ, 1982; SCHWARTZMAN, 2002).

Visando ilustrar essa questão, foi realizada, em 2002 e 2003, uma pesquisa de percepção pública da ciência (VoGT e Polino, 2003) em quatro países (Argentina, Brasil, Espanha e Uruguai). Apesar de ser um estudo de proporções relativamente pequenas, é interessante observar alguns resultados. No quesito "utilidade da ciência", a maioria dos entrevistados dos quatro países $(72 \%)$ con-

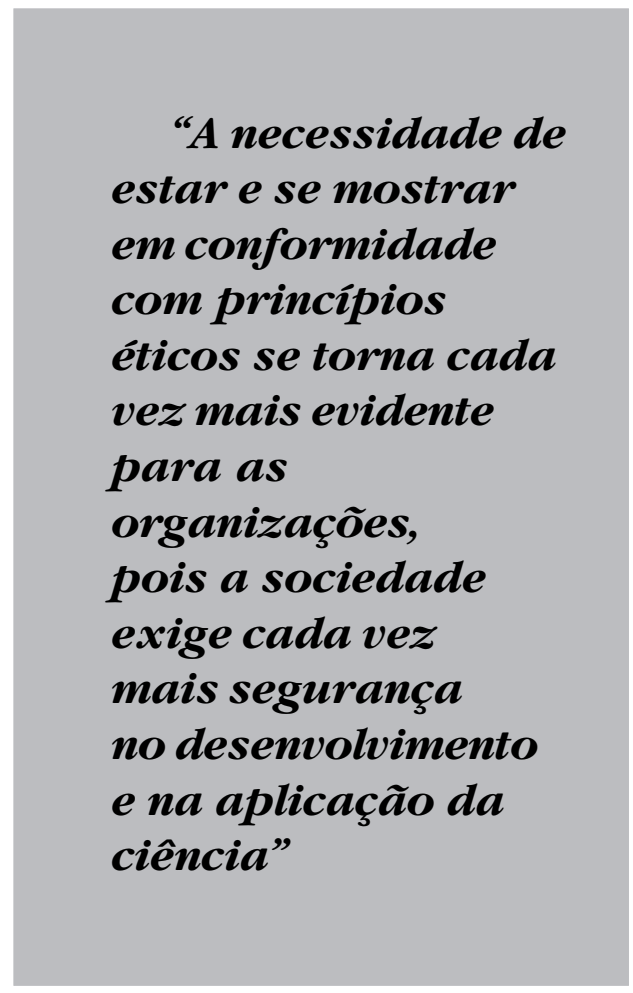

cordou que "o desenvolvimento da ciência e da tecnologia é o principal motivo de melhoria da qualidade de vida da sociedade". Entretanto, a grande maioria $(85,9 \%)$ nega que a ciência e a tecnologia possam solucionar todos os problemas.

A literatura chama a atenção para problemas de pequenas e de grandes proporções decorrentes da C\&T ou do 
seu mau uso. Ravetz (1982) lembra as bombas atômicas que caíram sobre os civis de Hiroshima e Nagasaki. Webster (1991) cita os casos de acidentes nucleares na usina atômica de Chernobyl (Ucrânia) e do reator nuclear "Three Mile Island", no estado da Pensilvânia, nos EUA. Valls (2001) lembra também o dramático acidente químico na fábrica da Union Carbide, em Bophal, na Índia.

Pesquisa realizada nos EUA, com cientistas da área médica dos Institutos Nacionais de Saúde (NIH), aponta que um terço dos 3.247 que responderam aos questionários afirmou ter cometido "alguma improbidade em seus estudos nos últimos três anos". O questionário incluía16 perguntas a respeito de máconduta científica, com diferentes níveis de gravidade, desde "você manteve registros inadequados de suas pesquisas?" até "você falsificou ou 'fabricou' dados de pesquisa?". Questionava ainda sobre a mudança do projeto, da metodologia ou dos resultados de estudos, por pressões de fontes de financiamento. Nessa questão, 15,5\% responderam afirmativamente, o que remete à questão do ambiente atuando na integridade da pesquisa. Apesar de o estudo se restringir à área médica nos EUA, os dados são preocupantes. Como o estudo evidencia, as "pequenas" infrações no mundo científico podem fazer mais mal à integridade da comunidade científica do que os grandes escândalos que de vez em quando são noticiados pela imprensa (Nogueira, 2005), visto que grandes escândalos têm destaque garantido na mídia, abrindo oportunidade aos atores para interferirem na redução dos danos ou na inibição de incidentes futuros. Entretanto, casos de fraude e adulteração de resultados podem causar danos não calculados, com impactos negativos à imagem da ciência.
Sobre integridade científica no Brasil, Azevedo (2005) relata que o Office of Research Integrity (ORI) dos EUA informou que, no período de 1994 a 2003, houve 133 casos de "má condução científica, 53\% por falsificação de dados, $29 \%$ por fabricação de resultados, $36 \%$ por ações conjuntas de fabricação/falsificação, entre outras desonestidades ocorridas com menores frequências".

Observa-se que não existe consenso na literatura sobre o estabelecimento de limites para a ciência. Há autores que defendem a total liberdade da ciência. Diniz (2004) considera que "cientistas são pessoas que questionam constantemente a maneira como vemos o mundo. Sem a liberdade para esse questionamento, a ciência perde seu sentido". Advoga que a ciência precisa ser livre "para ser um dos motores do desenvolvimento de um país". Bronowski (1979), que participou do Projeto Manhatan, que produziu as bombas de Hiroshima e Nagasaki, adverte sobre a importância de uma "ciência ética", a partir daquele momento em que o "homem-deus" substituíra Deus como mestre da natureza, com capacidade para dominá-la e destruí-la. Assim, sugere que sejam criados mecanismos para que a ciência regule a ciência.

Na reflexão sobre esse assunto, não se pode deixar de analisar o ethos da ciência, segundo a visão de Merton (1979, p.41), descrevendo quatro passos que chamou de "imperativos institucionais (mores)": universalismo, comunismo ou socialização, desinteresse e ceticismo organizado. Segundo esse autor, os mores da ciência se referem a prescrições morais e técnicas e "têm uma explicação racional metodológica, mas são moralmente obrigatórios, não somente porque são eficazes do ponto de vista do procedimento, mas também porque são considerados justos e bons". 
Ética é uma palavra rica em significados. Entretanto, para efeito deste trabalho, considerou-se uma definição mais restrita ao mundo do trabalho: conjunto de princípios morais de uma classe de profissionais ou de integrantes de uma organização, refletido na ação de cada indivíduo.

Cañas-Quirós (1998) propõe uma forma didática que permite compreender melhor o conceito e uso do termo "ética". Argumenta que ao se falar em ética como ciência normativa, referente à retidão dos atos humanos, com base em princípios racionais, trata-se de "ética geral", que remete à metafísica e à antropologia filosófica e busca explicar questões como liberdade, natureza do bem e do mal, felicidade e outros. Chama de "ética aplicada" aquela que busca levar para a prática os fundamentos gerais da ética. Os princípios básicos seriam sedimentados no plano individual, familiar e social. O nível social se subdivide em outros ramos, como ética internacional, econômica, profissional, institucional, entre outros.

\section{Ética na pesquisa agropecuária}

Ainda que a bioética seja um tema em expansão no meio acadêmico, sobre a ética na pesquisa agropecuária brasileira, do ponto de vista da comunidade científica, encontram-se questões éticas na literatura, apesar de alguns estudos não trazerem nos seus títulos a palavra ética. Esse tema é tratado como um dos dilemas da pesquisa científica no Brasil. Também há muito, por parte de estudiosos e da sociedade em geral, a discussão e expressão de preocupações com a ética em assuntos afetos à pesquisa agropecuária na literatura e na mídia eletrônica, digital e impressa. Citamse, entre outras, pesquisas biotecnológicas e utilização de animais em pesquisas.
No caso da biotecnologia, há leis no Brasil que regulam sua utilização (Lei de Biossegurança), inclusive com a criação de órgãos reguladores. No caso de animais, tem-se a Lei no 11.794 , de 08/02/2008, que regulamenta o inciso VII do $\int 1^{\circ}$ do art. 225 da Constituição Federal (Brasıl, 1988), estabelecendo procedimentos para o uso científico de animais. A Resolução 196/961, do Conselho Nacional de Saúde do Ministério da Saúde (MinIstÉRIO DA SAÚdE, 1996), estabelece diretrizes e normas regulamentadoras sobre pesquisa envolvendo seres humanos. Tem-se ainda no Brasil leis sobre a propriedade intelectual e outras que regulamentam segmentos da atividade agropecuária. Essas leis e normas, apesar de não versar diretamente sobre ética, trazem princípios éticos aplicáveis à pesquisa agropecuária.

Tem sido destacada a importância do estabelecimento e da busca por uma ética institucional claramente definida que, segundo Humberg, constitui "padrões de comportamento que correspondem a valores reais, aceitos e assumidos pelos componentes da organização, a partir de sua cúpula" (Humberg, 2002, p. 25). Este autor faz a seguinte analogia: "a ética é como a água: corre de cima para baixo", isto é, a empresa se parece com o seu dono. Os dirigentes devem ter e mostrar uma conduta ética adequada, pois caso não o façam, darão aos seus colaboradores o direito de fazer o mesmo. No caso de empresa pública, o "dono", que é a sociedade brasileira, se faz representar pelos seus dirigentes. Dessa forma, as instituições devem investir no padrão ético dos seus dirigentes em todos os níveis. Singer (1998), discorrendo sobre a tomada de decisões, cita duas possibilidades, que é o vazio ético absoluto, em que ele considera que há um desconhecimento total de considerações de natureza 
ética e um estágio pré-ético de pensamento, em que a consciência ética não está ainda totalmente desenvolvida. Essas duas possibilidades podem existir em uma organização e esta pode atuar no sentido do desenvolvimento da consciência ética, com estratégias semelhantes às da educação.

A Embrapa sempre procurou deixar claro para os empregados os princípios e valores da Empresa por meio de documentos e normas. Os Planos Diretores da Embrapa (PDE), instituídos desde o final da década de 1980, explicitam as grandes linhas de orientação para as atividades desenvolvidas pela Empresa, incluindo a missão, a visão de futuro, os valores, os objetivos e as diretrizes estratégicas. A ética é um dos valores que sempre esteve inserido nesses Planos. $\mathrm{O}$ Código de Ética da Embrapa, instituído em dezembro de 2004, traz alguns princípios de ética na pesquisa, em seu Capítulo IV. Normas internas também orientam os pesquisadores sobre condutas éticas referentes a alguns temas, como por exemplo, publicações.

\section{Procedimentos metodológicos}

A pesquisa teve caráter exploratório, qualitativo e quantitativo. A coleta de dados foi realizada no final do ano de 2005. Inicialmente, realizou-se a pesquisa qualitativa a partir de entrevistas individuais, com um roteiro semiestruturado, aplicado em 21 formadores de opinião. O resultado da análise de dados subsidiou a construção de um questionário que abordou o tema da ética na pesquisa agropecuária e que foi aplicado à população de 1.846 cientistas da Embrapa. Para se chegar a essa população, partiu-se do número total de pesquisadores (2.246), subtraídos aqueles que estavam afastados por licença de longo período, à disposição de outros órgãos, e os que não dispunham de e-mail. O índice de respostas ao questionário foi de $26,65 \%$ (492 pesquisadores). Esses dados foram tratados e analisados estatisticamente por meio de análises descritivas. Os resultados são apresentados a partir dos temas abordados na pesquisa quantitativa e alguns resultados da qualitativa, para efeito de comparação ou de comprovação.

A média de idade dos respondentes é de 46,34 anos (abaixo da média de idade da população pesquisada, que é de 48,17 anos); a média do tempo de serviço é de 16,49 anos (pouco abaixo da média da população pesquisada, que é de 17,39 anos); e $69 \%$ são do sexo masculino, e 31\% do sexo feminino (da população estudada, $25,95 \%$ são do sexo feminino).

O questionário obteve um percentual de respostas de 26,65\%. Pode-se inferir disso e das declarações dos participantes da pesquisa, que o tema desperta ou traduz o interesse dos pesquisados.

\section{Opinião dos atores sobre ética na pesquisa}

Trata-se de uma pesquisa de percepção. Robbins (1999, p. 62 e 63) define percepção como "um processo pelo qual indivíduos se organizam e interpretam suas impressões sensoriais a fim de dar sentido ao seu ambiente", não correspondendo necessariamente à realidade em si, mas à visão de cada um. A percepção está condicionada a características de quem percebe: atitudes, motivações, interesses, experiências e expectativas, entre outras; a fatores da situação: tempo, local de trabalho, situação social; e a fatores no alvo observado: novidade, movimento, som, tamanho, fundo e proximidade. 
Apesar da dificuldade de se compreender totalmente o processo da percepção e mesmo o fato de ela não constituir a realidade objetiva, é importante estudá-la, uma vez que "o comportamento das pessoas é baseado em suas percepções do que a realidade é, e não na realidade em si. O mundo como ele é percebido é o mundo que é comportamentalmente importante" (RobBIns, 1999, p. 62).

\section{Relação entre ciência, pesquisa e ética}

Sobre a relação entre ciência, pesquisa e ética, $63 \%$ da amostra (305 pessoas) acredita que "a ética, a ciência e a pesquisa devem se complementar"; 34\% (169 pessoas) acredita que "a ética deve estar acima da ciência e da pesquisa" (Figura 1).

A maioria dos pesquisadores da amostra e do grupo de formadores de opinião concorda que a ciência e a ética devem ter uma relação estreita ou a ética deve estar acima da ciência, representando $96,34 \%$ da pesquisa quantitativa e $67 \%$ (14 pessoas) da pesquisa qualitativa. Apenas um terço dos pesquisadores consultados considera que a ética está acima, antecedendo assim suas atividades.

Em que momento a ética deve ser levada em consideração na pesquisa

Opinaram que a ética deve ser levada em consideração em todo o processo de pesquisa $94,51 \%$ (465 pessoas), - as opções eram: na elaboração e na definição de propostas, na análise do projeto, na avaliação dos resultados, na seleção de projetos, em todo o processo de pesquisa, sendo permitido assinalar mais de uma alternativa. Houve uma distribuição mais ou menos semelhante, cuja percentagem variou de $16,46 \%$ (81 pessoas), na seleção dos projetos, a 19,11\% (94 pessoas), na elaboração das propostas (Figura 2).

Esse resultado vem ao encontro do obtido no item anterior "Relação entre ciência, pesquisa e ética”, onde, somados, 97\% reconhecem na ética um componente importante para ser aliado à pesquisa. Dessa forma, pela opinião dos atores ouvidos, fica claro que não só a avaliação técnica da pesquisa deve ser considerada, como

\section{Relação entre ciência, pesquisa e ética}
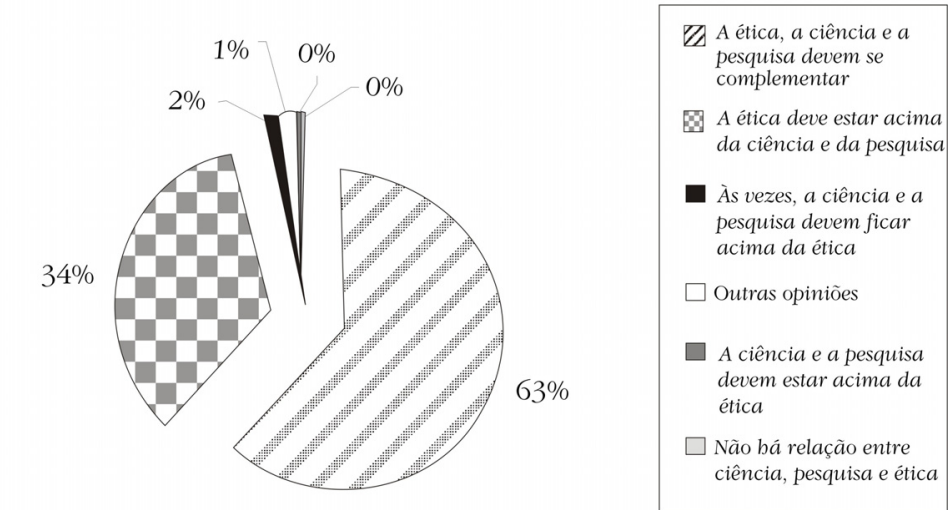

Figura 1: Relação entre ciência, pesquisa e ética (\%) 


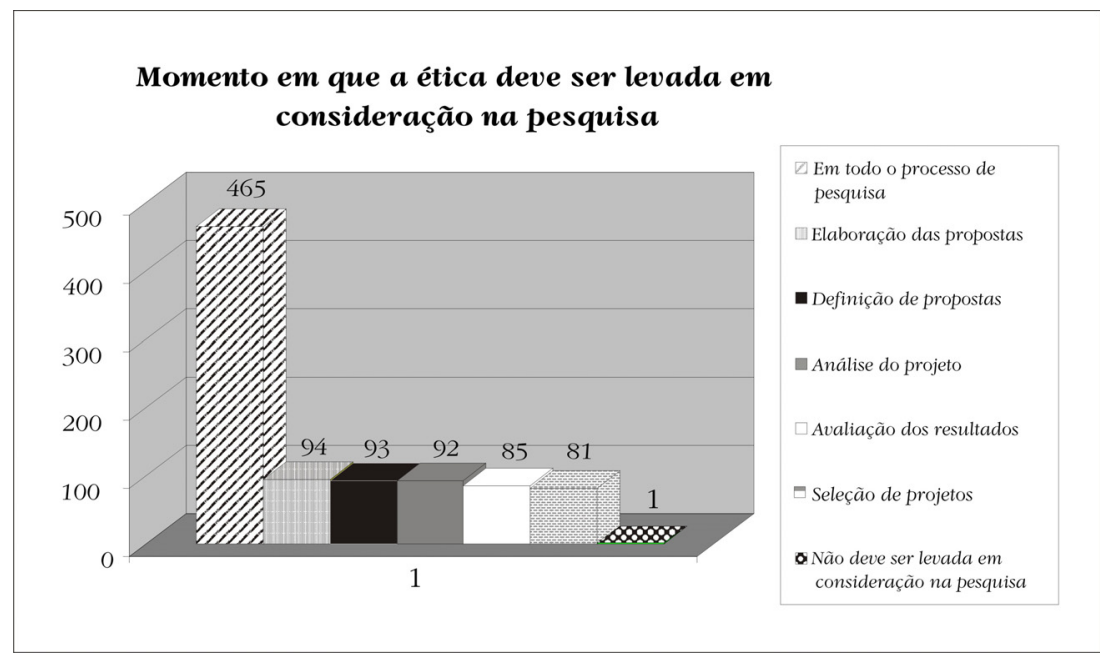

Figura 2: Momento em que a ética deve ser levada em consideração na pesquisa

também a avaliação ética, em todo o processo da pesquisa.

\section{Relação entre pesquisa agropecuária e bioética}

Quando perguntados sobre "Qual a relação entre a pesquisa agropecuária e bioética?", com quatro sugestões de respostas, $85 \%$ (417 pessoas) responderam que a "pesquisa agropecuária deve ser incluída nas discussões sobre bioética". Outros 13\% (64 pessoas) acreditam que "somente uma parte da pesquisa agropecuária deve estar incluída nas discussões sobre bioética". Um por cento ( 7 pessoas) acredita que "a pesquisa agropecuária não deve estar incluída nas discussões sobre bioética" (Figura 3).

Esse resultado guarda relação com as opiniões dos entrevistados na pesquisa qualitativa, na qual, dos 21 consultados, 20 reconhecem que há algum tipo de relação entre a pesquisa agropecuária e bioética. Assim, é opinião da quase totalidade das pessoas ouvidas que a pesquisa agropecuária deve estar incluída nas discussões sobre bioética. Nesse caso, há que se considerar a existência de um descompasso temporal, uma vez que as discussões sobre bioética já estão em curso há vários anos.

As definições sobre bioética encontradas e a Resolução 196/1996, do CNS/ MS, dão abrigo a essa convicção, já que define pesquisas envolvendo seres humanos, como "pesquisa que, individual ou coletivamente, envolva o ser humano de forma direta ou indireta, em sua totalidade ou partes dele, incluindo o manejo de informações ou materiais". A pesquisa agropecuária envolve seres humanos de forma indireta.

Crenças dos pesquisadores quanto à ética na pesquisa na Embrapa

Perguntados sobre "Quanto ao tema ética na pesquisa na Embrapa, você acredita que" (podendo assinalar mais de uma alternativa), em que as cinco primeiras afirmativas mais escolhidas foram extraídas do discurso dos entrevistados por ocasião da pesquisa qualitativa, 52,03\% (256 pessoas) assinalaram que a ética na pesquisa "Deve 


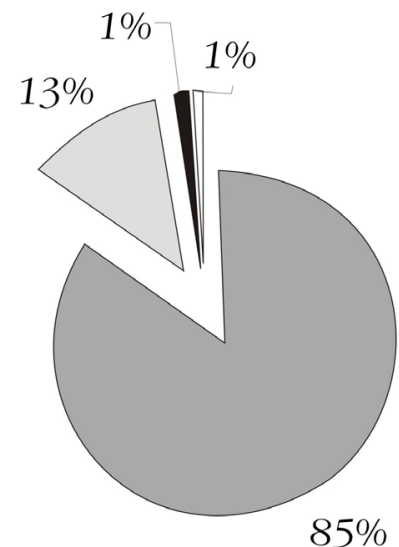

PA deve estar incluída nas discussões sobre bioética

$\square$ Somente uma parte da PA deve estar incluida nas discussões sobre bioética

PA não deve estar incluída nas discussões sobre bioética

$\square$ Outra opinião

Figura 3: Relação entre pesquisa agropecuária e bioética (\%).

obedecer a princípios éticos gerais, sem, contudo, limitar avanço do conhecimento". Essa preocupação com a limitação do avanço do conhecimento é recorrente no questionário e nas entrevistas. Nota-se no pesquisador uma preocupação com o não engessamento da ciência e da pesquisa.

A segunda questão mais assinalada foi "Necessita ser mais bem discutida na Embrapa pelos pesquisadores e pela direção da Empresa", com 49,19\% (242 pessoas), sendo uma reivindicação recorrente em todos os momentos da pesquisa a de que o tema deve ser mais discutido pelos pesquisadores e pela direção da Empresa.

A afirmativa "É preciso criar instâncias institucionais que permitam a interação entre a sociedade e a C\&T" foi opção de $44,72 \%$ (220 pessoas), em que fica clara a preocupação dos pesquisadores de melhorar a comunicação entre os que produzem C\&T e a sociedade, o que também é uma reivindicação atual dessa. A sociedade cada vez mais quer se inteirar dos resultados da C\&T, para poder também participar de alguma forma da tomada de decisão sobre alguns assuntos, principalmente sobre temas polêmicos.

"Não deve ser a única questão a definir se uma pesquisa vai avançar ou não", foi opção de 22,36\% (110 pessoas) e pode ser explicada pela quebra de paradigmas (KuHN, 1975). A ideia aqui defendida pode consistir no fato de a sociedade estar em constante mudança. Por exemplo, as vacinas, quando foram descobertas, provocaram na sociedade da época uma reação contrária muito forte. Entretanto, hoje são consideradas fundamentais para se evitar várias doenças, como também para a erradicação total delas. No mundo atual, deixar de vacinar crianças é que é considerado como uma atitude contrária a princípios éticos.

A ética na pesquisa "Não deve servir a outros objetivos, como por exemplo, limitar a ação dos países em desenvolvimento" foi assinalada por 16,87\% (83 pessoas) e tem a ver com a limitação da pesquisa pela ética, que parece ser compartilhada em todo o mundo. O século 21 começou com discussões sobre clonagem humana, e dessa vez não com base 
hipotética, mas real. Observam-se preocupações, inclusive dos países desenvolvidos, com relação à proibição ou não da clonagem humana no seu país, haja vista a possibilidade de perder o bonde da história ou o "status científico", caso em outros países seja liberada a clonagem e no seu, não. Isso remete à competição existente entre os países, que tem relação com a inovação (que pressupõe investimentos em P\&D) e com investimentos cumulativos em C\&T.

Apenas seis pessoas $(1,22 \%)$ acreditam que o tema "Está devidamente tratado na Embrapa, não necessitando de outras ações" e outras seis pessoas (1,22\%) expressaram outras opiniões (Figura 4).

Conduta ética dos novos pesquisadores em relação aos mais antigos

Sobre a questão "Você considera que há diferenças entre os novos pesquisadores e os mais antigos, em relação à conduta ética na pesquisa?", feita na entrevista semiestruturada, apesar de não terem sido apresentados para os respondentes os limites entre essas duas categorias, a grande maioria considera que tais diferenças existem e que podem ser observadas em vários aspectos, mas não tem certeza se haveria alguma relação com a ética ou com a ética na pesquisa. Inferências sobre essas diferenças há muitas, como por exemplo: maior comprometimento dos antigos para com a Empresa; diferenças na formação (os pesquisadores mais novos foram educados em outra realidade, foram escolarizados em período mais liberal e democrático); os novos são mais individualistas estão mais comprometidos com suas carreiras e teriam mais essa percepção da ética porque têm mais acesso à informação devido à tecnologia.

\section{Opinião sobre as normas de ética na pesquisa}

Princípios éticos em que os pesquisadores se baseiam na execução da pesquisa

Questionados sobre "Com relação aos princípios éticos na execução da pesquisa, você se baseia em:", a grande maioria,

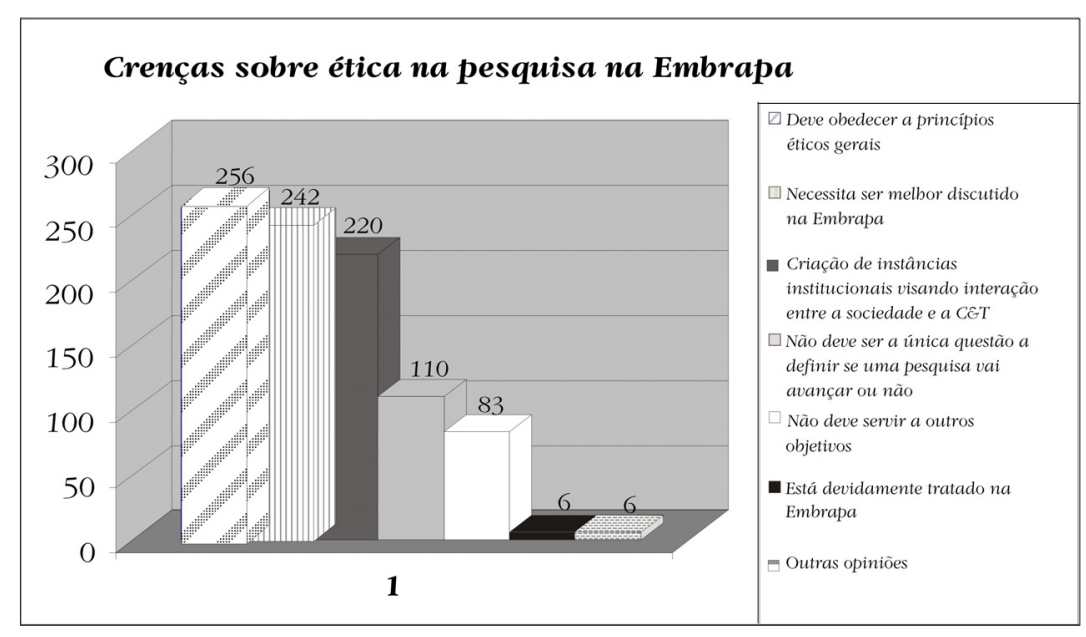

Figura 4: Afirmativas dos respondentes sobre o tema "ética na pesquisa" ( $\mathrm{n}^{\circ}$ de respostas) 
$85,16 \%$ (419 pessoas), respondeu que se baseia em seu código de ética pessoal. Como essa questão permitia assinalar mais de uma resposta, 55,49\% (273 pessoas) responderam se basear no código de ética de sua profissão, seguido do Código de Ética da Embrapa, com 46,95\% (231 pessoas); no Código de Ética do Servidor Público, com 16,26\% (80 pessoas); e "na ética da sua religião", com 14,84\% (73 pessoas). Três pessoas $(0,6 \%)$ acreditam que no trabalho de pesquisa não há necessidade de se considerar princípios éticos. Outras 4,27\% (21 pessoas) deram outros tipos de respostas (Figura 5). mento individual de cada pessoa manifestaria seus valores e princípios. Nem sempre, porém, os atos das pessoas são resultados de grandes reflexões, pois a maioria dos seus princípios já está internalizada e esses são manifestados naturalmente em suas ações, além do fato de que as informações necessárias a uma decisão envolvendo ciência de ponta sejam geralmente pouco conhecidas. Pode, também, haver mudanças em alguns aspectos do sistema de valores das pessoas, a qualquer tempo, decorrentes de novas reflexões.

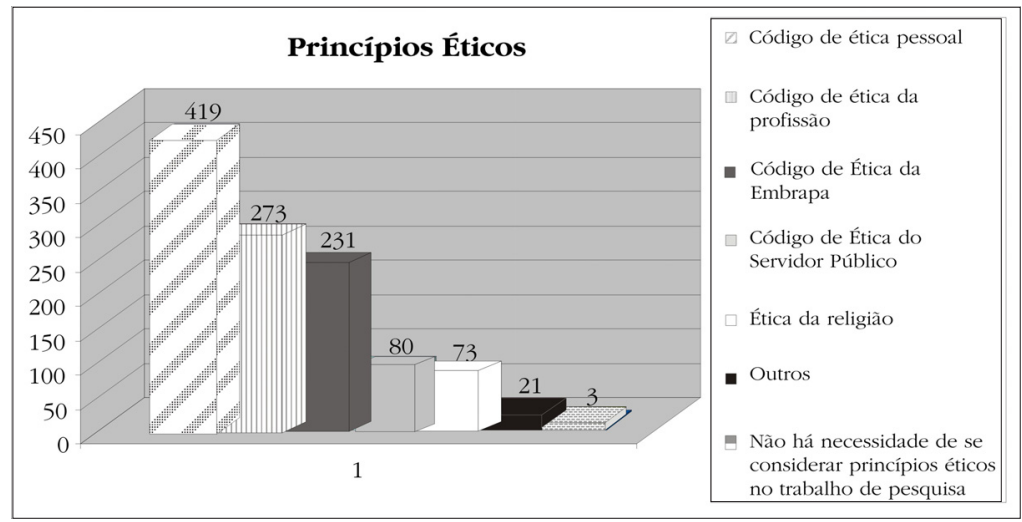

\section{Figura 5: Princípios éticos em que os pesquisadores se baseiam na execução da pesquisa ( $\mathrm{n}^{\circ}$ de respostas)}

Afirmaram que se baseiam no "Código de ética pessoal - princípios pessoais" 85,16\% dos participantes. Um código de ética pessoal é constituído por uma série de princípios e valores nos quais se baseia o comportamento. Está associado com a educação formal e informal, sendo formado ao longo da vida. Entende-se que as ações sejam julgadas por esse código individual, que determina o que se considera justo e correto e que deixa "a consciência tranquila”. Assim, em tese, o comporta-
O alto índice de respostas a essa alternativa $(85,16 \%)$ é compreensível, na medida que até em nossas pequenas ações recorre-se ao sistema de valores individuais. É também desejável, para viver bem, estar em paz consigo mesmo. Entretanto, o Código de Ética Pessoal, sendo individual, não necessariamente tem firme compromisso com o bem comum (ética geral), com a missão da instituição (ética institucional) ou com qualquer outra dimensão relacionada ao outro (alteridade). Ainda mais, o "livre arbítrio", que parece um 
atributo do ser humano, tende a deixar as pessoas muito à vontade para tomar decisões no plano individual, mesmo com riscos de individualismo.

$\mathrm{Na}$ tentativa de explicar esse resultado, pode acontecer de, por falta de conhecimento do Código de Ética da Embrapa (conforme índices apresentados adiante), que é uma norma institucionalizada, os pesquisadores recorrerem à instância pessoal, para balizar suas ações na condução da pesquisa. Nesse caso, tornase necessária a intervenção da Empresa, para divulgar melhor seu sistema de valores, que certamente visa objetivos gerais que individualmente podem não ser contemplados. Além disso, esse procedimento poderia contribuir para a redução de conflitos de interesses entre o pessoal e o institucional, entre o público e o privado. que os códigos de ética profissional sejam fortalecidos, em detrimento dos códigos de ética das instituições. Se assim o for, há risco de prevalecer padrões de conduta corporativos, que nem sempre condizem com o "bem comum", que deve ser objetivo de organismos públicos de pesquisa, como a Embrapa.

Afirmam basear-se no "Código de Ética da Embrapa" 46,95\% (231 pessoas). Em outra questão sobre o conhecimento do código, objeto da Deliberação no 16 , de $17 / 12 / 2004$, publicada em 10/01/2005, a maioria, 41\% (201 pessoas), respondeu desconhecê-lo; 38\% (188 pessoas) afirmaram que o conhecem superficialmente; 8\% (37 pessoas) afirmaram que conhecem somente os itens que se referem a pesquisa e 13\% (66 pessoas) declararam que conhecem todo o seu conteúdo (Figura 6).

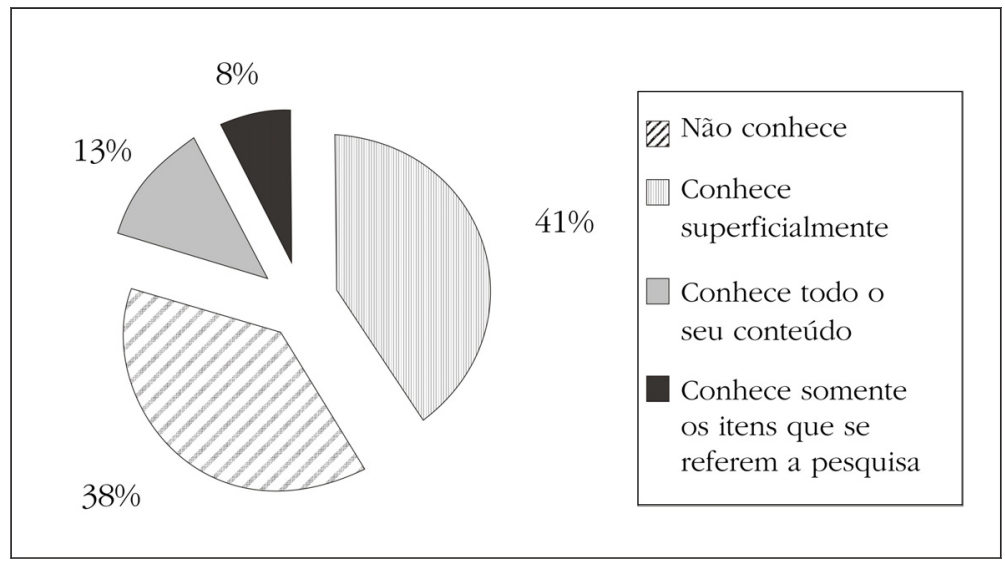

Figura 6: Pesquisadores que conhecem o Código de Ética da Embrapa (\%)

Baseiam-se no "Código de Ética Profissional" 55,49\% da amostra. Em geral, as profissões possuem códigos de ética que regulam a ação dos profissionais. Segundo Yeganiantz (1987), a tendência é
Por meio de análises realizadas, nota-se que dos 231 pesquisadores que responderam se basear no Código de Ética da Embrapa, 17,71\% (41) afirmam não conhecê-lo na questão posterior. Assim, fica evidente que 
poucos dos que afirmam agir conforme Código de Ética da Embrapa, como referência a suas atividades de pesquisa, o conhecem efetivamente. Também se pode afirmar que $87 \%$ dos respondentes (426 pessoas) não conheciam o Código de Ética da Embrapa em sua totalidade.

Como explicação para esse fato, podese recorrer à questão da "desejabilidade social”, que é um termo utilizado na psicologia e que explica a tendência que algumas pessoas têm de dar as respostas que elas acreditam ser as mais socialmente aceitas, devido a várias razões, como o fato de a pessoa querer repassar uma imagem melhor de si ou da instituição em que trabalha. Há temas, entretanto, onde a ocorrência desse fenômeno é maior, como, por inferência, o tema da ética, visto que está relacionado com valores considerados nobres pela maioria das pessoas.

Baseiam-se no "Código de Ética do Servidor Público" 16,26\% dos respondentes. Esse código foi aprovado pelo Decreto
1.171, de 22/06/94, e, sendo destinado ao Servidor Público Civil do Poder Executivo federal, estende-se aos empregados da Embrapa. Observa-se que o código é constituído de orientações gerais, não se referindo diretamente à atividade de pesquisa.

Afirmaram basear-se na "Ética da Religião" 14,84\% (73 pessoas). Esse resultado é inferior, em termos percentuais, às respostas a questões similares da pesquisa qualitativa, em que, perguntados sobre "Sua vinculação religiosa influencia a sua atividade de pesquisa?", 12 (de um total de 21) responderam "Não" e seis responderam "Sim".

\section{Conflitos entre princípios pessoais} e atividade de pesquisa na Embrapa

Sobre essa questão, uma proporção considerável, $52 \%$ (257 pessoas), respondeu "Não"; 38\% (185 pessoas) responderam "Sim" e 10\% (50 pessoas) responderam "Não me lembro" (Figura 7). Na pesquisa qualitativa, sobre o mesmo tema, a maioria (14 entrevistados) respondeu "Não".

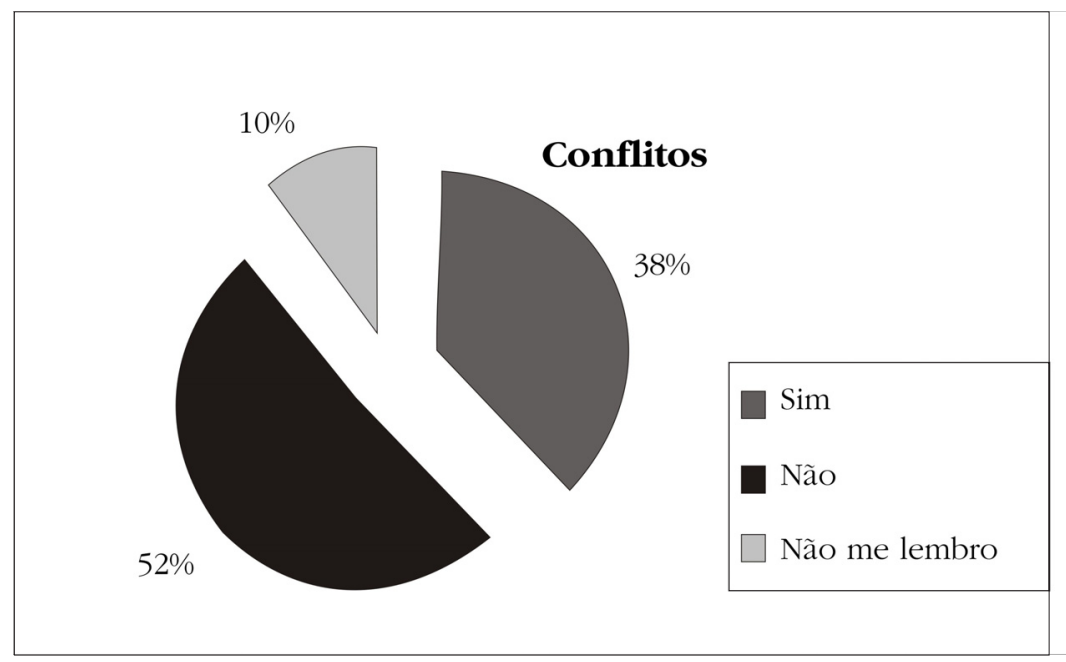

Figura 7: Conflitos entre princípios pessoais e atividade de pesquisa na Embrapa (\%) 
Princípios ou questões éticas na pesquisa agropecuária

Durante a realização desse trabalho houve várias instâncias (as entrevistas iniciais, as entrevistas semiestruturadas e os comentários apostos nos questionários) em que foi possível reunir sugestões de princípios ou questões éticas que poderiam ser analisadas, visando sua utilização na pesquisa agropecuária. As questões citadas pelos pesquisadores, como merecedoras de discussão, foram: manipulação de dados, divulgação precipitada de informações, roubo de ideias e materiais, competição, utilização de posição hierárquica indevidamente, busca de notoriedade, responsabilidade pela função pública, responsabilidade do pesquisador, adoção de diários de pesquisa, autoria e coautoria, conflitos de interesse, avaliações de questões ambientais e sociais, biopirataria, entre outras.

Embora alguns desses temas encontrem correspondência direta ou indireta no Código de Ética da Embrapa, a maioria das preocupações externadas pelos pesquisadores não está especificamente citada no Código. Isso ocorre porque a questão da ética, para efeito de regulação da conduta, está associada a, no mínimo, duas instâncias: a) os princípios; e b) as matérias reguladas. Os "princípios" correspondem às intenções maiores, às premissas básicas. Já a "matéria regulada" compreende o detalhamento das questões éticas. Para se chegar a um documento como esse, é necessário o envolvimento de todos os atores, em amplas discussões.

\section{Cumprimento dos princípios éticos da pesquisa pelos pesquisadores \\ Perguntados se "Os pesquisadores da} Embrapa, no exercício de suas atividades, estão cumprindo os princípios éticos da pesquisa", 38\% (188 pessoas) responderam "quase sempre"; 34\% (166 pessoas) declararam não saber; 17\% (84 pessoas) responderam "Sim"; 5\% (23 pessoas) responderam "Não" e 6\% (31 pessoas) expressaram sua opinião, que consideravam diferente das opções que foram apresentadas (ver Figura 8).

Nota-se que a certeza de que os pesquisadores estão cumprindo os

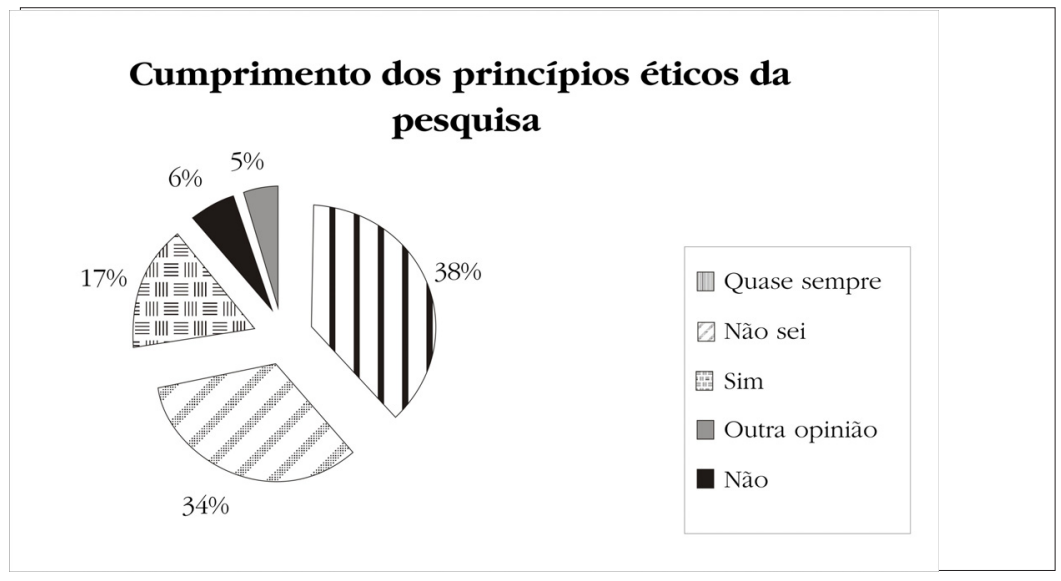

Figura 8: Percepção dos respondentes sobre cumprimento dos princípios éticos da pesquisa na Embrapa (\%) 
princípios éticos da pesquisa é muito baixa $(17 \%)$. Esse resultado pode ter ocorrido por diversos motivos, como: a) falta de conhecimento maior sobre o que seria ética na pesquisa; b) falta de conhecimento sobre um documento específico de ética na pesquisa, na medida em que $41 \%$ responderam não conhecer o Código de Ética da Embrapa, que contém um capítulo sobre o assunto; c) dificuldade de se avaliar todos os pesquisadores, devido à falta de dados; d) dificuldade em se situar na posição de avaliador postfacto; $e$ ) falta inserção na cultura da Empresa do conceito de ética e de ética na pesquisa.

\section{Como o grupo de formadores de opinião percebe a ética na pesquisa e as normas de ética na pesquisa na Embrapa}

As entrevistas com o grupo formador de opinião revelaram falta de clareza ou segurança com relação ao que seria ética ou ética na pesquisa. Entretanto, todos consideram importante a discussão e a maioria aceita um passivo nesse assunto ou acredita que é um tema novo e, como tal, deve estar na pauta de discussões tanto dos altos gestores como dos pesquisadores em geral.

Com relação à questão das normas de ética na pesquisa na Embrapa, obteve-se um resultado que vem ao encontro dos que já foram apresentados. $\mathrm{Na}$ entrevista semiestruturada, perguntados se "Você considera que a Embrapa tem normas específicas quanto à ética na pesquisa?”, dos 21 respondentes, nove afirmaram que não. Quatro pessoas ficaram em dúvida e oito pessoas responderam com certeza que sim. Dessas, uma não se lembra; três citam o Código de Ética da Embrapa (e um conjunto de normas que regem o funcionamento da Embrapa); outro acredita que "tem instrumentos e conhecimento bastante claros" e que tem procedimentos; outro acha que há várias normas que podem ser qualificadas como de ética; outro, ainda, afirma que "os documentos referenciais orientadores da formulação de pesquisa, existentes nos macroprogramas, contemplam os princípios gerais que norteiam a ética na empresa".

O estudo mostra a falta de consenso nessa questão, sendo que pesquisadores consideram que as várias normas existentes na empresa podem ser consideradas normas específicas de ética e outros entendem que não. Dos 11 chefes ouvidos, apenas seis acreditavam que havia normas específicas. É oportuno lembrar que a percepção sobre a existência das normas é igualmente importante à própria existência dessas, uma vez que na percepção podem estar incluídos o conhecimento e a internalização.

\section{Conclusões}

Com relação à ética em C\&T, concluise que há necessidade de refletir sobre os limites éticos da pesquisa, explicitando princípios básicos e padrões de conduta que deverão ser praticados pela comunidade científica. Isso contribuiria para coibir práticas indesejáveis ou configuradas como má-fé, buscando sempre a integridade e a credibilidade da ciência.

$\mathrm{Na}$ pesquisa, ficou evidenciado que a maioria dos atores ouvidos (97\%) reconhece a estreita relação entre a ciência, a pesquisa e a ética, e uma maioria (63\%) também acredita que a ética, a ciência e a pesquisa devem se complementar. Um terço dos atores (34\%) considera que a ética deve estar acima da ciência e da pesquisa. "A ética deve ser levada em consideração 
em todo o processo de pesquisa" é a opinião da quase totalidade dos atores $(94,51 \%)$, ficando assim muito clara a importância - do tema na pesquisa, na opinião dos pesquisadores ouvidos.

O estudo revelou, entretanto, que havia certo desconhecimento por parte de alguns gerentes e pesquisadores da Embrapa sobre o que seria especificamente "ética na pesquisa agropecuária". Por outro lado, ficou evidenciado que o tema despertava ou traduzia o interesse de todos os atores ouvidos, o que mostra um ambiente favorável à atuação da empresa em políticas, nessa área.

É relevante assinalar que pensar em ética não é uma tarefa fácil. As pessoas em geral não gostam de se envolver com o assunto, dada a complexidade do tema. Entretanto, o fato de ser complexo não exime profissionais com alto grau de instrução e formação, como os pesquisadores, de terem consciência e atitudes consoantes ao tema. Destaca-se também que, quando o assunto é ética, alguns pesquisadores afirmam que é "questão de berço". Sabemos, no entanto, que seria impossível supor que todas as novas e complexas questões que circunscrevem o avanço do conhecimento e das técnicas já estivessem equacionadas e incutidas na mentalidade de todos, como atributo comportamental a priori. Assim, é lícito considerar que, caso não se disponha dessa bagagem de princípios e conhecimentos, há sempre a possibilidade de se adquirir, pois o crescimento do ser humano em todas as dimensões ocorre, em tese, durante toda a sua vida. É, nesse sentido, perfeitamente possível aprender e internalizar princípios, sejam estes no campo pessoal, profissional etc.

O estudo mostrou que há necessidade da Embrapa investir na discussão e definição de princípios norteadores da conduta ética na pesquisa, buscando o envolvimento maciço do pessoal da carreira de P\&D, o que poderá contribuir como forma de proteger a empresa de atuações dentro de um "vazio ético" ou em estágio "pré-ético" de pensamento, conforme caracteriza Singer (1998). A participação, além de contribuir para um produto representativo, favorece a internalização e a conscientização, gerando corresponsabilidade.

Seria ainda estratégico investir em um procedimento de institucionalização de análise da dimensão ética nas pesquisas desenvolvidas. O objetivo não é a fiscalização, mas a interação positiva de consultores (que podem ser da própria empresa), externos às equipes de pesquisa. Esses desempenhariam a função pedagógica de lançar questões de natureza ética para alertar e conscientizar os pesquisadores sobre sua responsabilidade.

Entende-se que o presente estudo, que trata de um desafio inerente a uma instituição de pesquisa, tem caráter exploratório. Ainda há muito que descobrir e compreender sobre o tema.

(Artigo recebido em outubro de 2010. Versão final em fevereiro de 2011). 


\section{Notas}

* Os autores agradecem à Empresa Brasileira de Pesquisa Agropecuária, na pessoa de seus líderes e de seus pesquisadores, que proveram as condições para realização deste estudo.

1 Essa Resolução instituiu a Comissão Nacional de Ética em Pesquisa (CONEP) e os Comitês de Ética em Pesquisa (CEP). Site: http://www.ensp.fiocruz.br/etica/resolucoes.cfm\#pre, acesso em 14/mar./2010.

\section{Referências bibliográficas}

Azevedo, E. S. Integridade científica. Como anda o Brasil? Jornal da Ciência E-mail 2779. Disponível em: http://www.pucsp.br/pos/gerontologia/radar16.html. Acessado em: 01 jun. 2009.

Brasil, Ministério da SAúde. Resolução 196/96 do Conselho Nacional de Saúde/MS Sobre Diretrizes e Normas Regulamentadoras de Pesquisa envolvendo seres humanos. Diário Oficial da União, 10 de outubro de 1996.

Brasil. República Federativa do Brasil. Constituição. Brasília: Senado Federal, 1988. 292 p. Bronowski, J. The Common Sense of Science. Cambridge, MA: Harvard University Press, 1978. $154 \mathrm{p}$.

Cañas-Quirós, Roberto. Etica general y ética profesional. Revista Acta Académica, Universidad Autónoma de Centro América, Número 23, Noviembre 1998. Disponível em: http://www.uaca.ac.cr/acta/1998nov/rcanas.htm Acessado em: 03/abril/2007.

Diniz, Debora. A Ciência Perseguida. E-mail 2547. Disponível em: Jornal da Ciência, http://www.jornaldaciencia.org.br/ Detalhe.jsp?id=19450. Acesso em: 18 jun. 2006.

Humberg, M. E. Ética na política e na empresa: 12 anos de reflexões. São Paulo: Editora CLA, 2002. 114 p. Coleção ABERJE.

JonAs, Hans. Zur ontologischen Grundlegung einer Zukunftsethik. In: Philosophischen Untersuchungen und metaphysische Vermutungen. Frankfurt am Main e Leipzig, Insel, 1992.

Kunn, T. S. A Estrutura das Revoluções Científicas. São Paulo: Perspectiva, 1975.

Merton, R. K. Sociologia - Teoria e Estrutura. São Paulo: Editora Mestre Jou, 1970. 758 páginas.

Merton, R. K. Os Imperativos Institucionais da Ciência. In: DEUS, J. D. (Org.). A Crítica da Ciência. Rio de Janeiro: Zahar Editores, 1979. p. 37-52.

Nogueira, S. Um em três cientistas admite má-fé. Jornal da Ciência, n 2785, de 09 de junho de 2005. Disponível em: http:/ / www.jornaldaciencia.org.br/Detalhe.jsp?id=28866. Acesso em: 12 nov. 2009.

PAuwELs, E. Ethics for researchers: facilitating research excellence in FP7. Luxembourg: European Communities, 2007. Disponível em http://www.eurosfaire.prd.fr/7pc/doc/ health/article_EP-ethics-210607.pdf. Acesso em: 30/Abril/2010. 
Ravetz, J. History of Science. In: The New Encyclopaedia Britannica, vol. 16, Fifteenth Edition. Chicago, 1982. p. 366-375.

RobBins, S. P. Comportamento Organizacional. 8. ed. Rio de Janeiro: LTC, 1999. 489 p. SCHWARTZMan, S. Como os produtores de Ciência, tecnologia e Inovação "percebem" a sociedade? In: Papel e Inserção do Terceiro Setor no Processo de Construção e Desenvolvimento da Ciência, Tecnologia e Inovação. Rio de Janeiro: Academia Brasileira de Ciências e Instituto de Tecnologia Social, 2002. p. 32-35. Disponível em: http://www.schwartzman.org.br/ simon/ter_set.htm. Acesso em:11/dez./2009.

Singer, P. Ética Prática. 2. ed. São Paulo: Martins Fontes, 1998. 399 p.

Valls, A. L. M. Ciência da ética. In: ARIAS, G.; Fernandes, M. I. B. de M. (Ed.). Ciência e ética. Brasília, DF: Embrapa Informação Tecnológica, 2001. p. 57-73.

Viotti, E. B.; Macedo, M. M. de. Indicadores de Ciência, Tecnologia e Inovação no Brasil - Uma Introdução. In: ViotTi, E. B.; MACEDo, M. de M. (Ed.). Indicadores de Ciência, Tecnologia e Inovação no Brasil- Uma Introdução. São Paulo: UNICAMP, 2003. p. xviii-xxxix. Vogt, C.; Polino, C. (Org.). Percepción Pública de la Ciencia: Resultados de la Encuesta en Argentina, Brasil España y Uruguay. Campinas, SP: Editora da Unicamp, 2003. 187 p. Webster, A. Science, Technology, and Society: New Directions. New Brunswick, New Jersey: Rutgers University Press, 1991.

Yeganiantz, L. A ética na administração da pesquisa. In: XII Simpósio Nacional de Pesquisa em Administração de Ciências e Tecnologia. São Paulo, outubro de 1987. p. 103-117. 


\section{Resumo-Resumen-Abstract}

\section{Ética na pesquisa agropecuária: percepção dos pesquisadores da Embrapa Regina Lucia Ramos Lourenço e Marcel Bursztyn}

Esse trabalho apresenta os resultados de um estudo sobre a percepção dos pesquisadores da Empresa Brasileira de Pesquisa Agropecuária (Embrapa) a respeito da ética na pesquisa agropecuária. O estudo foi exploratório e adotou abordagens qualitativa e quantitativa. A pesquisa qualitativa utilizou entrevistas individuais semiestruturadas com 21 formadores de opinião (dirigentes, exdirigentes e ocupantes ou ex-ocupantes de cargos estratégicos) e serviu de base para a construção do questionário para a pesquisa quantitativa. Da população estudada, 1.846 pesquisadores, houve um retorno de $26,65 \%$ dos questionários. Os resultados da pesquisa revelaram grande interesse entre os pesquisadores ouvidos pelo tema objeto do estudo e ao mesmo tempo uma falta de clareza de parte deles sobre o que seria ética na pesquisa agropecuária. O estudo recomenda uma ampla discussão na Empresa sobre o tema, culminando na implantação de "gestão da ética" na pesquisa.

Palavras-Chave: Ética na pesquisa, integridade científica, pesquisa agropecuária, gestão da ética

\section{Ética en la investigación agrícola: las percepciones de los investigadores de Embrapa Regina Lucia Ramos Lourenç y Marcel Bursætyn}

El objetivo de este estudio es analizar las percepciones de los investigadores de la Empresa Brasileña de Investigación Agropecuaria (Embrapa) en relación con la ética en la investigación agrícola. El estudio fue exploratorio y los enfoques adoptados fueron de carácter cualitativo y cuantitativo. En la investigación cualitativa se utilizó la entrevista semiestructurada con 21 líderes de opinión (gerentes, ejecutivos y antiguos ocupantes o antiguos ocupantes de las posiciones estratégicas) y sirvió como base para la construcción de un cuestionario para la investigación cuantitativa. Del universo de población del estudio, 1846 investigadores, se tuvo un retorno de 26,65\% de los cuestionarios. Los resultados de las investigaciones nos permiten afirmar la existencia de un gran interés entre los expertos consultados por el sujeto y el objeto del estudio, mientras que hay una falta de claridad en una gran parte de ellos en lo que es la ética en la investigación agrícola. El estudio recomienda un amplio debate sobre el tema en la empresa, que culmine con la adopción de una "gestión de la ética" en la investigación.

Palabras clave: Ética en la investigación, integridad científica, investigación agrícola, gestión de la ética

\section{Ethics in agricultural research: perceptions of Embrapa's researchers}

\section{Regina Lucia Ramos Lourenço and Marcel Bursðtyn}

This paper presents the results of a study on the perception of researchers from the Brazilian Agricultural Research Corporation (Embrapa) about ethics in agricultural research. The study was exploratory and used qualitative and quantitative approaches. The qualitative research utilized semistructured individual interviews with 21 opinion makers (directors, former directors and strategic officers of the corporation) and served as basis for construction of the quantitative survey questionnaire. Of the population studied, 1846 researchers, 26,65 returned the questionnaire. The survey results allow us to affirm the existence of great interest, among the researchers interviewed, in the subject of this study and at the same time a lack of clarity about what is ethics in agricultural research. The study recommends an ample discussion with Embrapa culminating in the "ethical management" in research.

Keywords: Ethics in research, scientific integrity, agricultural research, ethical management 
Regina Lucia Ramos Lourenço

Especialista em Administração de Recursos Humanos pela pela Fundação Getúlio Vargas (FGV) e mestre em Desenvolvimento Sustentável pela Universidade de Brasília (UnB). É analista da Embrapa. Contato: ramos@sede.embrapa.br Marcel Bursztyn

Doutor em Desenvolvimento Econômico e Social pela Université de Paris I (Sorbonne) e em Economia pela Université de Picardie-França. É professor associado no Centro de Desenvolvimento Sustentável da UnB. É membro do Conselho de Ética na Pesquisa Agropecuária na França (INRA e CIRAD). Contato: marcel@unb.br 